\title{
Predicting the Body Weight Using Appropriate Regression Model in Beetal Goat Kids
}

\author{
S Gurdeep Singh ${ }^{1 *}$, Amitoz Kaur ${ }^{2}$ and Balwinder Kumar ${ }^{3}$ \\ ${ }^{1}$ Division of Livestock production, KVK Tarn Taran, Gadvasu, Punjab, India \\ ${ }^{2}$ Department of Animal Husbandry, VAS, Chatha, Jammu, J\&K. India \\ ${ }^{3}$ Deputy Director, KVK Tarn Taran, Gadvasu, Punjab, India \\ *Corresponding author: gurdeepkultaran443@gmail.com
}

\begin{abstract}
This paper deals with designing a cheap and easy-to-attain method to replace weighing for estimating the body mass of goats. Several models on the relationship of heart girth (HG) to live weight (LW) were used and data was collected on 50 Beetal goat kids ( 25 males and 25 females) of different age groups maintained at organized goat farm in Tarn taran district of Punjab. The animals were divided into four age groups as 0, 1, 2 and 3 months. To predict the body weight of Beetal goat kids four body measurements (height at wither, heart girth, body length and paunch girth) were recorded on each animal which was further used to develop the step wise multiple regression equations. Body measurements varied with increasing age of animals. In goat kids, the highest correlation $(r)$ was observed between body weight and heart girth at $0(r=0.701)$ and $1(r=0.762)$ months of age. Similarly height at wither at 2 month $(r=0.813)$ and paunch girth at 3 month $(r=0.825)$ of age.

These correlations between body weight and body measurements were positive and significant $(\mathrm{P}<0.01)$. The regression analysis indicated that live weight and body measurements (height at wither, heart girth, body length and paunch girth). Multiple regression analyses were used to calculate the prediction equations. The coefficient of determination $\left(\mathrm{R}^{2}\right)$ for weight estimation were for height at wither and paunch girth $(86.0 \%)$ at 3 month. It was concluded that body weight of goat kids can be estimated in field using body measurements taken with a tape in the absence of weighing scales.
\end{abstract}

Keywords: Beetal goat kids, Body weight, Wither, Heart girth and prediction equation

Knowing the small ruminants body mass is very useful for effective management, including monitoring growth and choosing replacement males and females, understanding medication doses and adjusting feed supply. The most ways to assess body mass is weighing animals with a spring balance, a steelyard balance or any suitable scale. However, such devices are too expensive for most of small farmers. The various lengths, heights and girths of live animals are measured to assess the relationship between these variables and the $L W$, in sheep (Valdez et al. 1997; Atta and El khidir 2004; Sowande and Sobola, 2008; Kunene et al. 2009; Oke and Ogbonnaya, 2011) or goat (Mohammed and Amin, 1997). For these reasons, this paper deals with girth measurements that are cheap and easy-to-attain for most farmers, and could help in monitoring weight of both growing and breeding goats. FAO have used height at withers as a prime indicator (Wilson, 1995). It is documented that there is a close relationship between the distance around an animal's heart girth and its body weight (Otoikhian et

How to cite this article: Singh, S.G., Kaur, A. and Kumar, B. (2020). Predicting the body weight using appropriate regression model in Beetal goat kids. Theriogenology Insight, 10(1): 01-06.

Source of Support: None; Conflict of Interest: None 
al., 2008). Enevoldson and Kristensen, (1997) reported that different models might be needed to predict body weight in different environmental conditions and breeds.

Goats being hardiest animals ever domesticated by man are a good source of income to a sizeable population of Punjab out of which Beetal goat breed is the most recognized breed known for its prolificacy and considered superior to it as it is more prolific and adapts more easily to different agro-ecological conditions and stall feeding. The Beetal goat breed is native to the districts of Gurdaspur, Amritsar and Ferozepur in Punjab. Amongst native breeds, the Beetal is one of the heaviest dairy type goat breeds, well known for milk production and has largely been used in cross-breeding and other goat improvement programmes.

Growth of kids, which is indicator of its physique and economic viability. Higher growth rate in goat farming is not only essential for profit, but also for higher production and reproduction efficiency, better survivability and for faster genetic improvement by decreasing generation interval and increasing replacement rate (Singh et al., 2009).

\section{MATERIALS AND METHODS}

The present survey research was taken out at organized goat farms and in field in Tarn taran district of Punjab during the year 2019-2020. During present research, total 50 Beetal goat kids were surveyed which includes 25 male and 25 female of different ages were taken which were divided into four groups of $0,1,2$, and 3 months of age. All kids were reared under intensive system of standard management practices. Kids were also allowed greenish succulent fodder ad libitum and creep mixture depending upon their body requirement from the age of $1^{\text {st }}$ month till 3 months. Fresh water was also provided for 24 hrs to the kids under intensive management system. The animals were provided routine deworming preparations as per approved schedule and guidelines. Body weight
(BW) was taken by electronic balance, Mean \pm S.E, correlation and regression for the body weight and different linear body measurements (HAW, BL and HG) were calculated. Body length (BL) was measured from the point of shoulder to the pin bone. . Paunch girth (PG) was circumferential measured around the stomach just before the hind legs. Heart girth (HG) represented the circumference of the chest just behind the fore legs and wither. Height at wither (HAW) was measured as the distance from the surface of the platform to the height at wither

\section{STATISTICAL METHODS}

GLM procedures of SAS (2004) were used so as to analyze the data statistically. Correlation coefficients between each of Body weight and with different body measurements (Heart girth, Punch girth, Height at wither, and Body length) were calculated. The coefficient of determination (R2) was used for evaluating and comparing different regressions models so as to determine the best fitted regression equation. For calculation of prediction equation, Simple and multiple regression analyses were used accordingly.

\section{RESULTS AND DISCUSSION}

Biometric measurments have been used to predict the body weight of goats without weighing balance and prediction equation with different comination of body measurments can be used to estimate live body weights of males and females at various ages pf a particular breed based on coefficient of determination [R]. (Alade et al 2008).

\section{Phenotypic Correlation between body weight and body measurements}

The average bodyweight and body measurements (Height at wither, Body length, Heart girth and Paunch girth) were recorded at different age groups for Beetal goat kids are presented 
in Table 1. The correlation of body weight at $0,1,2$ and 3 months age with different body measurements viz. Height at Wither, Heat Girth, Body Length and Paunch Girth were estimated and summarized in Table 2. Correlation studies indicated positive and highly significant $(\mathrm{P}<0.01)$ correlations between body weight and body measurements in all age group. Patil et al. (2013) reported highly significant $(\mathrm{P}<0.01)$ and positive correlation between body weights and body measurements (heart girth, body length and height at wither) at 1 and 3 month of age for Sangamneri goat kids. Similar results were also reported by Yakubu, (2010) in Yankasa lambs. The findings were in agreement to the results of Suranagi et al. (2005), Rahman et al. (2008) and Mule et al. (2014) at the age from birth to 3 months in kids. Heart girth and height at wither were highly correlated with body weight at 0-3 months of age followed by paunch girth. In conclusion, since the body measurements had high correlation with the body weight, this may be used as selection criteria in goats. However, further research is needed to investigate the relationship between the body weight with linear body measurements in same and other breeds of goats in different region of the country at different age with maximum number of observations.
Coefficient of determination $\left(\mathrm{R}^{2}\right)$ using Stepwise multiple regression analysis for different body measurements by taking various combinations at different ages in Beetal goat kids. Various prediction equations were developed for predicting body weight at different age by using various combinations of body measurements.

\begin{tabular}{cc}
\hline Prediction equations & Age (month) \\
\hline$Y_{i}=\alpha+\beta_{2} x_{2}+\beta_{3} x_{3}$ & $(0 \mathrm{~m})$ \\
$Y_{i}=\alpha+\beta_{2} x_{2}+\beta_{3} x_{3}+\beta_{4} x_{4}$ & $(1 \mathrm{~m})$ \\
$Y_{i}=\alpha+\beta_{1} x_{1}+\beta_{2} x_{2}+\beta_{4} x_{4}$ & $(2 \mathrm{~m})$ \\
$Y_{i}=\alpha+\beta_{1} x_{1}+\beta_{4} x_{4}$ & $(3 \mathrm{~m})$ \\
\hline
\end{tabular}

At the age of birth ( 0 month) the combination of the variables i.e. height at wither and heart girth were found to be statistically significant at 1 percent level of significance implying that with the combination of described variables contribute $63.10 \%$ to predict the body weight of Beetal goat kids. At the age of one month the value of coefficient of determination was found higher for the combination of heart girth, body length and paunch girth $(79.30 \%)$ as compared to combinations of other body measurements indicating that at one month of age the best combination for the estimation of body weight in Beetal goat kids. Similarly, at the age of 2 months the value of coefficient of determination was higher for height at wither, heart girth and

Table 1: Mean (+ S.E.) for body weight and linear body measurements in Beetal goat kids

\begin{tabular}{cccccc}
\hline Age (month) & Body Weight (kg) & Height at Wither (cm) & Heart Girth (cm) & Body Length (cm) & Paunch Girth (cm) \\
\hline 0 & $2.98 \pm \mathbf{0 . 0 2 9}$ & $34.23 \pm \mathbf{0 . 0 2 3}$ & $36.80 \pm \mathbf{0 . 3 2 2}$ & $29.67 \pm \mathbf{0 . 1 8 6}$ & $31.54 \pm \mathbf{0 . 2 0 9}$ \\
1 & $5.87 \pm \mathbf{0 . 0 8 9}$ & $44.37 \pm \mathbf{0 . 3 2 3}$ & $42.72 \pm \mathbf{0 . 2}$ & $36.21 \pm \mathbf{0 . 3} 13$ & $42.36 \pm \mathbf{0 .} 254$ \\
2 & $9.32 \pm \mathbf{0 . 1 5 6}$ & $48.95 \pm \mathbf{0 . 4 1 2}$ & $47.54 \pm \mathbf{0 .} .291$ & $40.34 \pm \mathbf{0 . 4 5 4}$ & $50.08 \pm \mathbf{0 . 5} 520$ \\
3 & $10.66 \pm \mathbf{0 . 1 2 3}$ & $51.22 \pm \mathbf{0 . 2 1 2}$ & $51.34 \pm \mathbf{0 . 3 1 3}$ & $45.78 \pm \mathbf{0 . 5 2 3}$ & $52.99 \pm \mathbf{0 . 2} 289$ \\
\hline
\end{tabular}

Table 2: Coefficient of correlation between body weight $(\mathrm{kg})$ and other linear body measurements

\begin{tabular}{ccccc}
\hline Age (Month) & HG & PG & HAW & BL \\
\hline 0 & $0.701^{* *}$ & $0.406^{* *}$ & $0.622^{* *}$ & $0.634^{* *}$ \\
1 & $0.762^{* *}$ & $0.591^{* *}$ & $0.697^{* *}$ & $0.548^{* *}$ \\
2 & $0.812^{* *}$ & $0.696^{* *}$ & $0.813^{* *}$ & $0.418^{* *}$ \\
3 & $0.786^{* *}$ & $0.825^{* *}$ & $0.789^{* *}$ & $0.433^{* *}$ \\
\hline
\end{tabular}

Heart girth (HG) and Paunch girth (PG), Height at wither (HAW), Body length (BL)

Online ISSN: 2277-3371 
Table 3: Stepwise multiple regression analysis of body weight for body measurements estimation in Beetal goat kids

\begin{tabular}{|c|c|c|c|c|c|c|c|c|}
\hline $\begin{array}{c}\text { Age } \\
\text { (month) }\end{array}$ & Prediction Equations & $\alpha$ & $\beta_{1}$ & $\boldsymbol{\beta}_{2}$ & $\boldsymbol{\beta}_{3}$ & $\boldsymbol{\beta}_{4}$ & $R^{2}(\%)$ & $\overline{\mathbf{R}}^{2}(\%)$ \\
\hline \multirow{3}{*}{0} & $Y_{i}=\alpha+\beta_{1} x_{1}+\beta_{2} x_{2}+\beta_{3} x_{3}+\beta_{4} x_{4}$ & $\begin{array}{c}-2.008 * * \\
(0.588)\end{array}$ & $\begin{array}{l}0.0223 \\
(0.015)\end{array}$ & $\begin{array}{l}0.068 * * \\
(0.022)\end{array}$ & $\begin{array}{l}0.069 * * \\
(0.022)\end{array}$ & $\begin{array}{l}-0.019 \\
(0.017)\end{array}$ & 67.30 & 63.10 \\
\hline & $Y_{i}=\alpha+\beta_{1} x_{1}+\beta_{2} x_{2}+\beta_{3} x_{3}$ & $\begin{array}{c}-2.221 * * \\
(0.578)\end{array}$ & $\begin{array}{c}0.030 \\
(0.014)\end{array}$ & $\begin{array}{l}0.059 * * \\
(0.170)\end{array}$ & $\begin{array}{r}0.070^{* *} \\
(0.200)\end{array}$ & & 66.20 & 63.10 \\
\hline & $Y_{i}=\alpha+\beta_{2} x_{2}+\beta_{3} x_{3}$ & $\begin{array}{c}-2.098^{* *} \\
(0.589)\end{array}$ & $\begin{array}{c}0.073^{* *} \\
(0.015)\end{array}$ & $\begin{array}{l}0.079 * * \\
(0.020)\end{array}$ & & & 63.56 & 61.20 \\
\hline \multirow{2}{*}{1} & $Y_{i}=\alpha+\beta_{1} x_{1}+\beta_{2} x_{2}+\beta_{3} x_{3}+\beta_{4} x_{4}$ & $\begin{array}{c}-9.660 * * \\
(1.509)\end{array}$ & $\begin{array}{c}0.059 \\
(0.049)\end{array}$ & $\begin{array}{l}0.159 * * \\
(0.035)\end{array}$ & $\begin{array}{l}0.135^{* *} \\
(0.029)\end{array}$ & $\begin{array}{c}0.050 \\
(0.029)\end{array}$ & 82.30 & 79.00 \\
\hline & $Y_{i}=\alpha+\beta_{2} x_{2}+\beta_{3} x_{3}+\beta_{4} x_{4}$ & $\begin{array}{c}-8.877^{* *} \\
(1.281)\end{array}$ & & $\begin{array}{c}0.179 * * \\
(0.025)\end{array}$ & $\begin{array}{c}0.147^{* *} \\
(0.026)\end{array}$ & $\begin{array}{c}0.057^{*} \\
(0.028)\end{array}$ & 79.30 & 78.60 \\
\hline \multirow[b]{2}{*}{2} & $Y_{i}=\alpha+\beta_{1} x_{1}+\beta_{2} x_{2}+\beta_{3} x_{3}+\beta_{4} x_{4}$ & $\begin{array}{c}-17.126^{* *} \\
(1.997)\end{array}$ & $\begin{array}{l}0.202 * * \\
(0.070)\end{array}$ & $\begin{array}{l}0.160 * * \\
(0.053)\end{array}$ & $\begin{array}{c}0.049 \\
(0.034)\end{array}$ & $\begin{array}{l}0.131^{* *} \\
(0.036)\end{array}$ & 83.10 & 82.20 \\
\hline & $Y_{i}=\alpha+\beta_{1} x_{1}+\beta_{2} x_{2}+\beta_{4} x_{4}$ & $\begin{array}{c}-16.000^{* *} \\
(1.989)\end{array}$ & $\begin{array}{c}0.240 * * \\
(0.065)\end{array}$ & $\begin{array}{c}0.154^{* *} \\
(0.053)\end{array}$ & & $\begin{array}{c}0.125^{* *} \\
(0.035)\end{array}$ & 82.20 & 80.70 \\
\hline \multirow{3}{*}{3} & $Y_{i}=\alpha+\beta_{1} x_{1}+\beta_{2} x_{2}+\beta_{3} x_{3}+\beta_{4} x_{4}$ & $\begin{array}{c}-25.570 * * \\
(2.312)\end{array}$ & $\begin{array}{c}0.205^{* *} \\
(0.069)\end{array}$ & $\begin{array}{c}0.090 \\
(0.089)\end{array}$ & $\begin{array}{c}0.028 \\
(0.032)\end{array}$ & $\begin{array}{c}0.325 * * \\
(0.045)\end{array}$ & 87.90 & 86.40 \\
\hline & $Y_{i}=\alpha+\beta_{1} x_{1}+\beta_{2} x_{2}+\beta_{4} x_{4}$ & $\begin{array}{c}-24.648^{* *} \\
(2.305)\end{array}$ & $\begin{array}{c}0.209^{* *} \\
(0.069)\end{array}$ & $\begin{array}{c}0.111 \\
(0.084)\end{array}$ & & $\begin{array}{l}0.323^{* *} \\
(0.045)\end{array}$ & 86.00 & 85.30 \\
\hline & $Y_{i}=\alpha+\beta_{1} x_{1}+\beta_{4} x_{4}$ & $\begin{array}{c}-23.433^{* *} \\
(2.134)\end{array}$ & $\begin{array}{c}0.280^{* *} \\
(0.043)\end{array}$ & & & $\begin{array}{l}0.340^{* *} \\
(0.043)\end{array}$ & 87.00 & 86.20 \\
\hline
\end{tabular}

** Significant $(\mathrm{P}<0.01)$; Significant $(\mathrm{P}<0.05)$.

$Y_{i}=$ Body weight in $\mathrm{kg}, \alpha=$ intercept of the best fit straight line; $x_{1}=$ Height at wither $x_{2}=$ Heart girth, $x_{3}=$ body length, $x_{4}=$ paunch girth in $\mathrm{cm} ; \beta_{1}, \beta_{2}, \beta_{3}, \beta_{4}=$ Partial regression co-efficient of body weight on height at wither, heart girth, body length, paunch girth respectively. $\mathrm{R}^{2}=$ coefficients of determination and $\overline{\mathrm{R}}^{2}=$ adjusted coefficients of determination.

paunch girth $(82.20 \%)$ as compared to other body measurements. Hence, for prediction of body weight in Beetal goat kids, the best combination was found with the height at wither, heart girth and paunch girth. It was clear from various prediction equations that at the 3 months of age, the prediction of body weight with combination of height at wither and paunch girth was found best predictor variables $(86.00 \%)$ among various age groups in Beetal goat kids. The present models were developed by Iqbal et al. (2013) in Beetal goat for estimation of body weight from various body measurements. It was found that the high phenotypic correlation between heart girth $(\mathrm{cm})$ and body weight $(\mathrm{kg})$ that strongly entails the importance of relationship between heart girth and body weight as body weight predictor. It was also found that heart girth was included in combination of various body measurements except at the age of 3 months. The present study was found corroborated to the findings of Kamarudin et al. (2011) and Ravimurugan et al. (2013) who reported that the heart girth is the best predictor for the estimation of body weight. It is concluded that the heart girth was found to be a useful tool in this regard. The higher $\mathrm{R}^{2}$ value and smaller MSE obtained in this study using a single or multiple predictor variable indicated that all the linear body measurements used as independent variables were good estimators of body weight in goat. 


\section{CONCLUSIONS}

The body weight and different body measurements were significantly correlated with each other which clearly indicates that body measurements can be used for estimation of body weight in the field where weighing scales are not usually available. The chest girth alone or in combination with other two measurements can be used for prediction of body weight with better accuracy. Since heart girth has a high correlation with the body weight, this may be used as a selection criterion to improve body weight indirectly so the most practical way to estimate the live weight of goats is by measuring the Heart girth of the goats. Previous reports have shown positive and significant relationship between the body weight and linear body measurements (body length, height at withers and heart girth) and further selection based on the body measurements could improve meat production which is quite significant in the present findings. Hence there is a dire need of comprehensive study and further validation of research to investigate the relationship between body weights with linear body measurements in large sample size of goat breeds.

\section{ACKNOWLEDGMENTS}

The authors acknowledges the sincere efforts of sarpanches of villages. The logistic support received from the KVK Tarn Taran, Gadvasu is also gratefully acknowledged.

\section{REFERENCES}

Alade, N.K., Raji, A.O. and Atiku, M.A. 2008 Determination of appropriate model for the estimation of body weight in goats. Journal of Agricultural and Biological Science, 3(4): 52-57.

Atta, M. and Khidir, O.A. 2004. Use of heart girth, wither height and scapuloischial length for prediction of live weight of Nilotic sheep. Small Ruminant Research, 55: 233-237.

Benyi, K.A. 1997. Estimation of live weight from chest girth in pure and crossbred WAD goats. Tropical Animal Health Production, 29: 124-128.
Chitra R., Rajendra S., Prassana D. and Kirubakaran A. 2012. Prediction of body weight using appropriate regression model in Malabari goat. Veterinary World, 5(7): 409-411.

Enevoldsen, C. and Kristensen, T. 1997. Estimation of body weight from body size measurements and body condition scores in dairy cows. Journal of Dairy Science. 80:1988-1995.

Iqbal, M., Javed, K. and Ahmad N. 2013. Prediction of body weight through body measurement in Beetal goats. Pakistan Journal of Science, 65(4): 458-459.

Kamarudin, N.A., Omar, M.A. and Marimuthu, M. 2011. Relationship between body weight and linear body measurements in boer goats. $6^{\text {th }}$ Proceedings of the Seminar on Veterinary Sciences, pp. 68-73.

Kunene, N.W., Nesamvuni, A.E. and Nsahlai, I.V. 2009. Determination of prediction equations for estimating body weight of Zulu (Nguni) sheep. Small Ruminant Research, 84: 41-46

Mohammed, I.D and Amin, J.D 1997. Estimating body weight from morphometric measurements of Sahel (Borno White) goats. Small Ruminant Research, 24: 1-5.

Mule, M.R., Barbind, R.P. and Korake, R.L. 2014. Relationship of body weight with linear body measurement in Osmanabadi goats. Indian Journal of Animal Research, 48(2): 155-158.

Nayak, S., Sahu, G. and Mohapatra, A.K. 2008. Study on management practices, phenotypic and reproductive characteristics of Ganjam sheep under range conditions of Orissa. SAARC J. Agric., 6(2): 93-106.

Oke, U.K. and Ogbonnaya, E.O. 2011. Application of Physical Body Traits in the Assessment of Breed and Performance of WAD Sheep in a Humid Tropical Environment. Livestock Research for Rural Development, 23, Artic24 http://www.lrrd. org/lrrd23/2/oke23024.htm

Otoikhian, C.S.O., Otoikhian, A.M., Akporhuarho, O.P. and Isida-homan C. 2008. Correlation of body weight and some body measurement parameters in Quda sheep under extensive management system. African Journal of General Agriculture, 17: 129-133.

Patil, B.S., Pachpute, S.T. and Dhage, B.S. 2013. Growth performance of Sangamneri goats under field conditions. Indian Journal of Small Ruminants, 19(2): 151-155. 
Rahman, A.S., Khandoker, M.A. Husain, S.S., Apu, A.S., Mondal, A. and Notter, D.R. 2008. Morphometric characterization and relationship of body weight with linear body measurements in black Bengal buck. Bangladesh Journal of Animal Science, 37(2): 8-16.

Ravimurugan, T., Thiruvenkadan, A.K., Sudhakar, K., Panneerselvam, S. and Elango, A. 2013. The estimation of body weight from body measurements in Kilakarsal sheep of Tamil Nadu, India. Iranian Journal of Applied Animal Science, 3(2): 357-360.

Russel, A.J.F., Doney, J.M. and Gunn, R.G. 1969. Subjective assessment of body fat in live sheep. Journal of Agriculture Science, 72: 451-454.

SAS. 2004. SAS, ver 9.1. Qualification Tools User's Guide. SAS Institute, Inc, Cary, NC,USA.

Salako A.E. and L.O. Ngere. 2002. Application of multifactorial discriminant analysis in the morphometric structural differentiation of the WAD and Yankusa sheep in the humid south-west Nigeria. Nigerian Journal of Animal Production, 29: 163-167.

Singh, M.K., Raj, B., Kumar, A., Sisodiya, H.S. and Singh, N.P. 2009. Production performance of Gohilwadi goats under range conditions. Indian Journal Animal Sciences, 79(6): 587-593.
Sowande, O. and Sobola, O. 2008. Body measurements of west African dwarf sheep as parameters for estimation of live weight. Tropical Animal Health and Production, 40: 433-439.

Suranagi, M.D., Shettar, V.B. and Biradar, U.S. 2005. Prediction equation for body weight in Bidri goats. Karnataka Journal of Agriculture Science, 18(3): 773-776.

Wilson, T.R. 1995. Livestock Production Systems: The Tropical Agriculturalist. Macmillan Education. Nairobi, Kenya.

Yakubu, A. 2010. Path coefficient and path analysis of body weight and biometric traits in Yankasa lambs. Slovak Journal of Animal Science, 43(1): 17-25.

Valdez, C.A., Tupas, D.G.A. and Matias, J.B. 1997. Determination of body weight in sheep using external body measurements. Philippine Journal of Veterinary Medicine, 34: 25-31. 